\title{
Review of: "Randomized controlled open label trial on the use of favipiravir combined with inhaled interferon beta-1b in hospitalized patients with moderate to severe COVID-19 pneumonia"
}

\author{
ÖNDER ÖZTÜRK
}

Potential competing interests: The author(s) declared that no potential competing interests exist.

First of all, I would like to congratulate all the authors who contributed to the study. We have come face to face with a pandemic that we can rarely encounter in our professional life. What we learned over the years as we tried to heal our patients without knowing about the treatment and its side effects. We started to fight the pandemic with the knowledge and experience we gained.

It has been suggested that the drug called hydroxychloroquine, which we used in the early stages of the pandemic, was not effective in studies and even not to be used due to its side effects $(1,2)$. Considering that each country applies its own treatment protocols, it is a drug that is primarily used in our country, but it is not used at the moment.

Due to the lack of an effective antiviral in the COVID-19 pandemic, current antiviral drugs have been used. Whether these drugs are sufficient or not has been tried to be shown by studies. The effectiveness of favipiravir was explained as the drug causing a rapid decrease in viral load within 4 days and demonstrating up to $88 \%$ clinical improvement in patients with mild to moderate COVID-19 (3). The effectiveness of favipiravir $(4,5)$ was also showed in different studies where 198 studies related to favipiravir appear in PubMed. In this context, we published a case series in which we demonstrated the efficacy in patients using favipiravir (6). We found Favipiravir to be effective in the treatment of COVID-19 patients and in reducing admissions to the ICU. This might be attributed to the prevention of virus replication and to reduction of the antigenic load of the COVID-19 virus and cytokine production (6). Another study conducted in our country shows that its effectiveness is not different from other treatments (7). An open-labelled randomized trial did not show any benefit from the early prescription of the drug compared with the late prescription, in patients with mild to moderate SARS-CoV-2 (8). However, favipiravir may emerge as a valuable drug in the treatment of mild to moderate symptomatic SARS-CoV-2 infected cases, but larger RCTs are urgently needed before this drug can be unreservedly recommended (9). There have been a lot of conflicting results in the literature about the favipiravir not being effective and should not be preferred in the COVID-19 pandemic. Because of these results, although favipiravir is one of the first choice drugs in my country, patients do not want to use it. Contrary to these opinions, we suggest that favipiravir treatment is effective when we use it in the early period and reduces the number of intensive care unit admissions. 
References:

1- Cavalcanti AB, Zampieri FG, Rosa RG, Azevedo LCP, Veiga VC, Avezum A, Damiani LP, Marcadenti A, Kawano-Dourado L, Lisboa T, Junqueira DLM, de Barros E Silva PGM, Tramujas L, Abreu-Silva EO, Laranjeira LN, Soares AT, Echenique LS, Pereira AJ, Freitas FGR, Gebara OCE, Dantas VCS, Furtado RHM, Milan EP, Golin NA, Cardoso FF, Maia IS, Hoffmann Filho CR, Kormann APM, Amazonas RB, Bocchi de Oliveira MF, Serpa-Neto A, Falavigna M, Lopes RD, Machado FR, Berwanger O; Coalition Covid-19 Brazil I Investigators. Hydroxychloroquine with or without Azithromycin in Mild-to-Moderate Covid-19. N Engl J Med. 2020 ;383(21):2041-2052.

2-RECOVERY Collaborative Group, Horby P, Mafham M, Linsell L, Bell JL, Staplin N, Emberson JR, Wiselka M, Ustianowski A, Elmahi E, Prudon B, Whitehouse T, Felton T, Williams J, Faccenda J, Underwood J, Baillie JK, Chappell LC, Faust SN, Jaki T, Jeffery K, Lim WS, Montgomery A, Rowan K, Tarning J, Watson JA, White NJ, Juszczak E, Haynes R, Landray MJ. Effect of Hydroxychloroquine in Hospitalized Patients with Covid-19. N Engl J Med. $2020 ; 383(21): 2030-2040$.

3- Mishra SK, Tripathi T. One year update on the COVID-19 pandemic: Where are we now? Acta Trop. 2021 Feb;214:105778. doi: 10.1016/j.actatropica.2020.105778.

4-Ghasemnejad-Berenji M, Pashapour S. Favipiravir and COVID-19: A Simplified Summary. Drug Res (Stuttg). $2021 ; 71(3): 166-170$.

5-Sreekanth Reddy O, Lai WF. Tackling COVID-19 Using Remdesivir and Favipiravir as Therapeutic Options. Chembiochem. $2021 ; 22(6): 939-948$.

6- Öztürk Ö, Bağlan V, Kaya O, Temel NE, Ünal O, Ayyıldız AV, Şirin MC, Şirin FB, Yılmaz RG, Akcam FZ, Çakır M, Akkaya A. Effectiveness of Favipiravir prior to Admission to the Intensive Care Unit in COVID-19 PneumoniaRespir Case Rep. 2020; 9(3): 99-103.

7- Özlüşen B, Kozan Ş, Akcan RE, et al. Effectiveness of favipiravir in COVID-19: a live systematic review [published online ahead of print, 2021 Aug 4]. EurJ Clin Microbiol Infect Dis. 2021;1-9.

8- Doi Y, Hibino M, Hase R, Yamamoto M, Kasamatsu Y, Hirose M, Mutoh Y, Homma Y, Terada M, Ogawa T, Kashizaki F, Yokoyama T, Koba H, Kasahara H, Yokota K, Kato H, Yoshida J, Kita T, Kato Y, Kamio T, Kodama N, Uchida Y, Ikeda N, Shinoda M, Nakagawa A, Nakatsumi H, Horiguchi T, Iwata M, Matsuyama A, Banno S, Koseki T, Teramachi M, Miyata M, Tajima S, Maeki T, Nakayama E, Taniguchi S, Lim CK, Saijo M, Imai T, Yoshida H, Kabata D, Shintani A, Yuzawa Y, Kondo M. 2020. A prospective, randomized, open-label trial of early versus late favipiravir therapy in hospitalized patients with COVID-19. Antimicrob Agents Chemother 64:e01897-20. https://doi.org/10.1128/AAC .01897-20

9-Agrawal U, Raju R, Udwadia ZF. Favipiravir: A new and emerging antiviral option in COVID-19. Med J Armed Forces India. 2020;76(4):370-376. 